\title{
EVALUASI NILAI KONDISI PERKERASAN JALAN NASIONAL DENGAN METODE PAVEMENT CONDITION INDEX (PCI) MENGGUNAKAN APLIKASI ROAD EVALUATION AND MONITORING SYSTEM (REMS) (Studi Kasus : Ruas Jalan Prambanan - Pakem).
}

\author{
Fakhri Muhammad $^{1)}$,Ary Setyawan ${ }^{2)}$, Suryoto $^{3)}$
}

\begin{abstract}
1)Mahasiswa Program Studi Teknik Sipil Fakultas Teknik Universitas Sebelas Maret 2), 3) Dosen Program Studi Teknik Sipil Fakultas Teknik Universitas Sebelas Maret Jl. Ir. Sutami 36 A, Kentingan Surakarta 57126, Telp (0271) 647069, Fax 662118 Email : fakhrimhd@gmail.com
\end{abstract}

\begin{abstract}
Along with the development of the era, technology is also more advanced as well as in the evaluation of road surface pavement conditions. In PCI method it takes a relatively long time and accuracy to do, depending on the number of observed segments. In 2017, Infrasoft developers released web-based software for monitoring, survey reporting, and road damage analysis called REMS (Road Evaluation and Monitoring System). This research aims to analyze the level of road surface pavement conditions on Prambanan - Pakem road with PCI method using survey form for collecting the data damage then calculates to obtain the PCI value and PCI method using REMS.

This research is done by dividing 30 segments that start from STA $0+450$ until STA $15+000$. Evaluate the condition of the pavement surface using the Pavement Condition Index (PCI) method, with obtained data from the field then write down the results on the available form. While the PCI method by using REMS only need to input damage data to the smartphone and analysis results will be directly available on website infrasoft.id.

The result of evaluation of the surface condition of a pavement of Prambanan - Pakem STA 0+450 until STA $15+000$ using manual PCI method yielded 77.4 with the category "Satisfactory". The result of the Pavement Condition Index (PCI) method using Road Evaluation and Monitoring System (REMS) application on the segment was obtained by 80.3 with the category "Satisfactory". Comparison of analysis results of manual PCI method and PCI REMS from a total of 30 segments, obtained 15 segments having the percentage of deviation less than or equal to $1 \%$. This is due to the difference in accuracy in the graph reading (DV and CDV) and in the PCI method for selection of CDV values selected from the highest values, but for PCI REMS it chooses the value in the first order.
\end{abstract}

Keywords : Pavement Condition Index, REMS, Apps

\section{Abstrak}

Seiring berkembangnya zaman maka teknologi pun juga semakin maju begitu juga dalam evaluasi kondisi permukaan perkerasan jalan raya. Dalam metode PCI dibutuhkan waktu relatif lama dan ketelitian untuk dilakukan, tergantung pada banyaknya segmen yang diteliti. Pada tahun 2017 developer Infrasoft mengeluarkan perangkat lunak berbasis web untuk monitoring, pelaporan survey dan analisa kerusakan jalan yang dinamakan REMS (Road Evaluation and Monitoring System). Penelitian ini bertujuan menganalisis tingkat kondisi permukaan perkerasan jalan pada ruas jalan Prambanan - Pakem dengan metode PCI menggunakan lembaran form survey untuk mendapatkan data kerusakan lalu menghitung nilai PCI nya dan metode PCI menggunakan aplikasi REMS.

Penelitian ini dilakukan dengan membagi 30 segmen yaitu mulai dari STA 0+450 sampai STA 15+000. Evaluasi kondisi permukaan perkerasan menggunakan metode Pavement Condition Index (PCI), dengan data yang diperoleh dari lapangan dan menuliskan hasilnya pada form yang tesedia. Sedangkan evaluasi PCI dengan menggunakan REMS hanya perlu menginput data kerusakan dan hasil analisisnya akan langsung tersedia pada website infrasoft.id.

Hasil evaluasi kondisi permukaan perkerasan Jalan Prambanan - Pakem STA 0+450 sampai STA 15+000 menggunakan metode PCI Manual menghasilkan nilai sebesar 77.4 dengan kategori "Satisfactory". Hasil perhitungan metode Pavement Condition Index (PCI) dengan menggunakan aplikasi Road Evaluation and Monitoring System (REMS) pada ruas tersebut didapatkan nilai sebesar 80.3 dengan kategori "Satisfactory". Analisis perbandingan nilai kondisi PCI manual dan PCI REMS dari total 30 segmen, diperoleh 15 segmen yang mempunyai pesentase simpangan kurang dari atau sama dengan $1 \%$. Hal ini disebabkan karena perbedaan keakuratan dalam pembacaan grafik ( $D V$ dan $C D V$ ) dan dalam metode PCI untuk pemilihan nilai CDV, dipilih dari nilai paling tinggi tetapi untuk PCI REMS diambil nilai dengan urutan pertama.

Kata Kunci : Pavement Condition Index, REMS, Aplikasi

\section{PENDAHULUAN}

Perkerasan jalan sering kali mengalami kerusakan secara fungsional maupun struktural sebelum mencapai umur rencananya yang biasanya disebabkan oleh kelebihan muatan yang tidak sesuai pada tahap perencanaan. Menurut Bina Marga No. 03/MN/B/1983 tentang Manual Pemeliharaan Jalan, jenis kerusakan jalan dibedakan atas retak ( cracking ), distorsi, cacat permukaan (disintegration), pengausan (polished aggregate), kegemukan (bleeding or flushing) ,penurunan pada bekas penanaman utilitas. Maka dari itu adanya pemeliharaan jalan yang dilakukan secara rutin untuk mengembalikan kondisi jalan tersebut. 
Ruas Jalan Prambanan - Pakem merupakan ruas jalan Nasional Luar Kota dari Kota Yogyakarta yang menjadi jalur penghubung antara Kota Magelang dan Kota Yoyakarta. Jalan ini termasuk kategori Jalan Nasional golongan III C dengan lebar 4 m, memiliki 2 lajur dan 2 arah tanpa median. Jalan Prambanan - Pakem menjadi jalan nasional menurut UU no 38 tahun 2004. Lalu lintas pada jalan Prambanan - Pakem selain banyak kendaraan jenis motor dan mobil yang lewat, jalan ini juga banyak dilewati truk-truk angkut dengan muatan besar karena truk tidak diperbolehkan melalui kota, sehingga ruas jalan Prambanan - Pakem dikhawatirkan telah terjadi kerusakan pada permukaan perkerasan. Maka perlu adanya evaluasi kerusakan permukaan perkerasan Jalan Prambanan - Pakem. Evaluasi kondisi permukaan perkerasan jalan raya nasional Prambanan - Pakem, dapat diperoleh dengan mencari nilai PCI (Pavement Condition Index) yakni dengan mengidentifikasi tipe-tipe kerusakan yang terjadi sesuai dengan indeks-indeks tingkat kerusakan.

Seiring berkembangnya zaman maka teknologi pun juga semakin maju begitu juga dalam evaluasi kondisi permukaan perkerasan jalan raya. Dalam metode PCI dibutuhkan waktu relatif lama dan ketelitian untuk dilakukan, tergantung pada banyaknya objek yang diteliti. Pada tahun 2017 developer Infrasoft mengeluarkan perangkat lunak berbasis web untuk monitoring, pelaporan survey dan analisa kerusakan jalan yang dinamakan REMS (Road Evaluation and Monitoring System). Aplikasi ini berbasis web pendukung, analisa dan monitoring survey dengan metode PCI, dengan visualisasi data dan hasil survey menggunakan map koordinat system, grafik dan table hasil analisa. Oleh karena itu adanya aplikasi ini bertujuan untuk memudahkan pengguna untuk mengevaluasi jalan dengan menggunakan metode PCI dengan cara menginput data kerusana berupa jenis dan dimensi pada kerusakan tersebut kemudian hasil PCI tersebut akan keluar tanpa harus menghitung dan membaca grafik serta table yang jumlahnya cukup banyak dan menyita waktu.

REMS (Road Evaluation Monitoring System) pada saat ini (2018) belum dapat digunakan secara resmi karena masih dalam tahap pengembangan, oleh karena itu akan dilakukan validasi aplikasi untuk mengetahui aplikasi dapat berjalan dengan hasil yang akurat sesuai metode PCI. Aplikasi ini diharapkan dapat membantu pengguna untuk mengevaluasi jalan agar lebih efisien sehingga dapat menindaklanjuti secepatnya untuk memperbaiki jalan yang dievaluasi.

\section{LANDASAN TEORI}

\section{Perkerasan Jalan}

Perkerasan jalan adalah campuran antara agregat dan bahan ikat yang digunakan untuk melayani beban lalu lintas. Berdasarkan bahan pengikatnya perkerasan jalan dibagi menjadi 3 jenis, yaitu perkerasan lentur (flexible pavement) dengan bahan pengikat aspal, perkerasan kaku (rigid pavement) dengan bahan pengikat semen, dan perkerasan komposit (composite pavement) yang merupakan gabungan dari keduanya dengan komposisi tertentu dari masingmasing bahan pengikat.

\section{Perkerasan Lentur (Flexible Pavement)}

Adalah perkerasan yang menggunakan aspal sebagai bahan pengikatnya dan bersifat lentur serta dapat memikul dan menyebarkan beban lalu lintas ke tanah dasar yang telah dipadatkan melalui berbagai lapisan. Lapisan lapisan tersebut adalah lapisan permukaan (surface coarse), lapisan pondasi atas (base coarse), lapisan pondasi bawah (sub-base coarse), tanah dasar (sub grade).

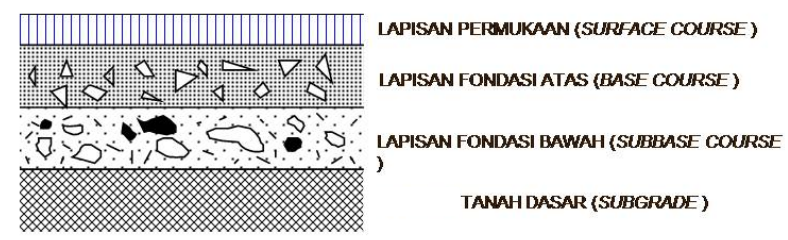

Gambar 1 Susunan Lapis Perkerasan Lentur

\section{Definisi Jalan Nasional}

Menurut UU No. 38 th 2004 pasal 18, jalan nasional merupakan jalan arteri dan kolektor yang menghubungkan antar ibukota provinsi dalam sistem jalan primer. Jalan nasional diberi kode ruas jalan yang selanjutnya dalam perundang-undangan disebut sebagai nomor rute. Nomor rute yaitu kode dalam bentuk angka yang digunakan sebagai identitas dari satu ruas jalan nasional. Sedangkan rute adalah kumpulan ruas jalan yang menghubungkan satu tempat dengan tempat lain secara menerus. 


\section{Kondisi Jalan}

Kondisi jalan adalah suatu hal yang sangat perlu diperhatikan dalam menentukan program pemeliharaan jalan. Menurut Departemen Pekerjaan Umum Dirjen Bina Marga (1992), jalan dengan kondisi baik adalah jalan dengan permukaan perkerasan yang benar-benar rata, tidak ada gelombang dan tidak ada kerusakan permukaan.

\section{Metode PCI}

Menurut ASTM D6433-07 PCI (Pavement Condition Index) peringkat numerik dari kondisi perkerasan yang berkisar dari 0 hingga 100, dengan 0 merupakan kondisi terburuk dan 100 merupakan kondisi terbaik. Data PCI didapatkan melalu survey kerusakan kondisi permukaan jalan secara visual yang teridentifikasi berdasarkan tiap jenis kerusakan.

Menentukan unit sampel

Untuk luasan satu sampel perkerasan lentur adalah sekitar $232 \mathrm{~m}^{2}$ (2500 sq.ft) agar nilainya akurat. Untuk menentukan jumlah minimum unit sampel (n) yang harus disurvey adalah menggunakan persamaan berikut:

$n=\frac{N s^{2}}{\frac{e^{2}}{4}(N-1)+s^{2}}$

dimana :

$N=$ jumlah total unit sampel dalam suatu bagian perkerasan,

$e=$ kesalahan yang diizinkan dalam estimasi dari bagian $P C I(e=5)$,

$s=$ standar deviasi dari $P C I$ antara unit sampel di dalam bagiannya (untuk perkerasan lentur, $s=10$ ).

Identifikasi Jenis Kerusakan

Berdasarkan Shahin (1994) jenis kerusakan jalan berjumlah 19 yaitu alligator cracking, bleeding, block cracking, bums and sags, corrugation, depression, edge cracking, joint reflection, lane/shoulder drop off, longitudinal and transverse cracking, patching and utility cut patching, polished aggregate, potholes, railroad crossings, rutting, shoving, slippage cracking, swell, weathering and ravelling. Tingkat kerusakan yang digunakan berjumlah 3 tingkat yaitu Low Severity Level (L), Medium Severity Level (M), dan High Severity Level (H)

Kerapatan (Density)

Merupakan nilai presentase yang didapatkan dengan membagi total luasan kerusakan atau panjang dengan luasan sampel unit berdasarkan jenis kerusakan. Rumus yang digunakan adalah :

Density $=\frac{A d}{A s} \times 100 \%$,

atau

Density $=\frac{L d}{A s} \times 100 \%$

dengan :

Ad $=$ Luas total jenis kerusakan untuk tiap tingkat kerusakan $\left(\mathrm{m}^{2}\right)$

$\mathrm{Ld} \quad=$ Panjang total jenis kerusakan untuk tiap tingkat kerusakan $(\mathrm{m})$

As $\quad=$ Luas total unit segmen $\left(\mathrm{m}^{2}\right)$

\section{Deduct Value}

Deduct Value merupakan nilai pengurangan untuk tiap jenis kerusakan yang diperoleh dari kurva hubungan antara Deduct Value dengan nilai Density dan tingkat kerusakan. Berikut merupakan contoh grafik $D V$

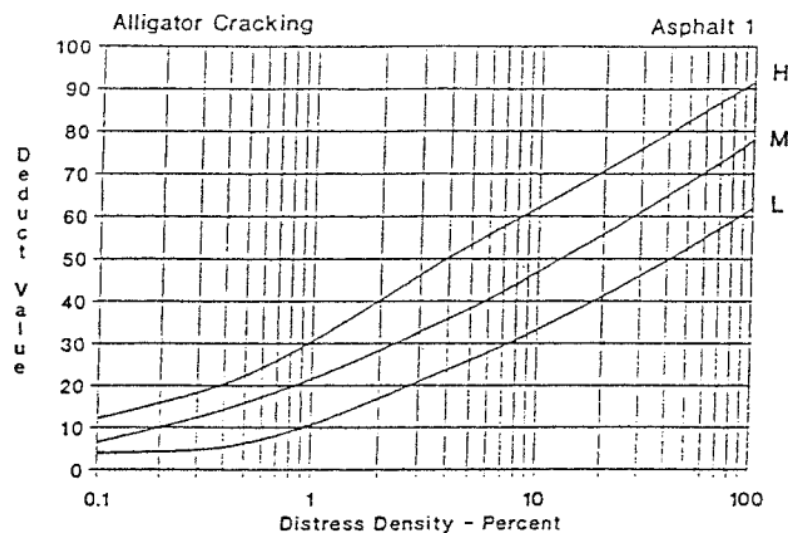


Gambar 2 Kurva Deduct Value untuk Alligator cracking

Nilai izin Deduct Value (m)

Perhitungan terhadap jumlah data deduct value dalam suatu segmen yang lebih dari 1 jenis. Jumlah data DV akan direduksi sampai sejumlah $\mathrm{m}$, termasuk bagian desimal. Jika data yang tersedia kurang dari nilai $\mathrm{m}$, maka seluruh data DV pada segmen tersebut dapat digunakan. Rumus perhitungan nilai $\mathrm{m}$ sebagai berikut

$\mathrm{m}=1+(9 / 98) \times(100-\mathrm{HDV})$

dengan :

$\mathrm{m} \quad=$ nilai izin $\mathrm{DV}$

$\mathrm{HDV}=\mathrm{DV}$ terbesar

Total Deduct Value (TDV) dan Corrected Deduct Value (CDV)

Nilai pengurangan total (TDV) adalah nilai total dari individual nilai pengurangan untuk tiap-tiap jenis kerusakan dan tingkat kerusakan yang ada pada suatu unit sampel penelitian.

Nilai pengurangan terkoreksi diperoleh dari kurva hubungan antara nilai TDV dan CDV dengan pemilihan lengkung kurva sesuai dengan jumah nilai individual deduct value yang mempunyai nilai lebih besar dari 2 . Nilai CDV dapat ditentukan dari grafik hubungan seperti yang disajikan pada Gambar 3 (sumber : MDP Bina Marga, 2013)

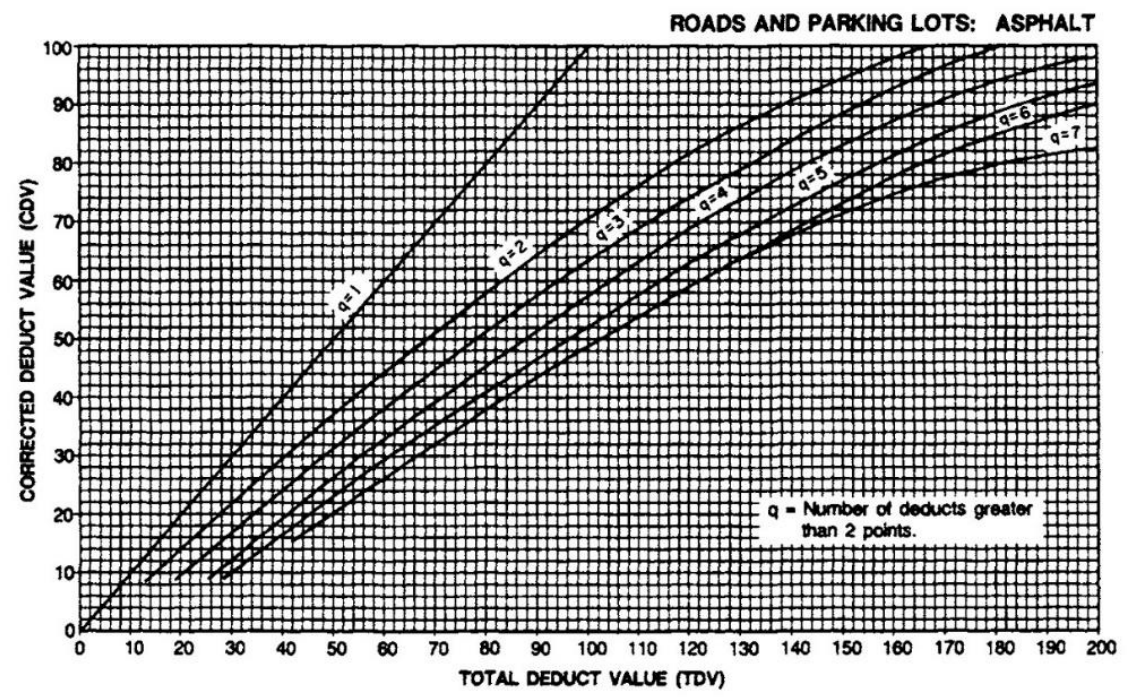

Gambar 3 Grafik hubungan antara TDV dengan CDV

Nilai PCI

Jika nilai CDV telah diketahui, maka nilai-nilai PCI untuk tiap unit dapat diketahui dengan persamaan di bawah ini :

$\mathrm{PCI}_{(\mathrm{s})}=100-\mathrm{CDV}$

dengan :

$\mathrm{PCI}_{(\mathrm{s})}=$ Pavement Condition Index untuk tiap unit.

$\mathrm{CDV}=$ Corrected Deduct Value untuk tiap unit.

Untuk nilai PCI secara keseluruhan maka :

PCI $=\frac{\Sigma P C I_{(s)}}{N}$

dengan :

PCI = Nilai PCI perkerasan keseluruhan.

$\mathrm{PCI}_{(\mathrm{s})} \quad=$ Pavement Condition Index untuk tiap unit.

$\mathrm{N} \quad=$ Jumlah unit.

Setelah diketahui nilai $P C I$, skala tingkat kerusakan dilihat dari gambar skala di bawah ini : 


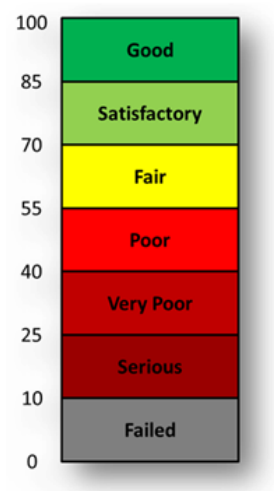

Gambar 4 Rating Kondisi Perkerasan Berdasarkan Nilai PCI

\section{PCI REMS}

Road Evaluation and Monitoring System (REMS) adalah perangkat lunak berbasis web yang memudahkan pengguna untuk melakukan monitoring kerusakan jalan berdasarkan survey yang dilakukan. Metode yang didukung oleh REMS adalah metode PCI, dengan visualisasi data dari hasil survey menggunakan map koordinat sistem, grafik dan table hasil analisa. Berikut merupakan contoh input visualisasi data pada aplikasi REM yaitu berupa jenis kerusakan dan dimensi kerusakan setiap segmen.

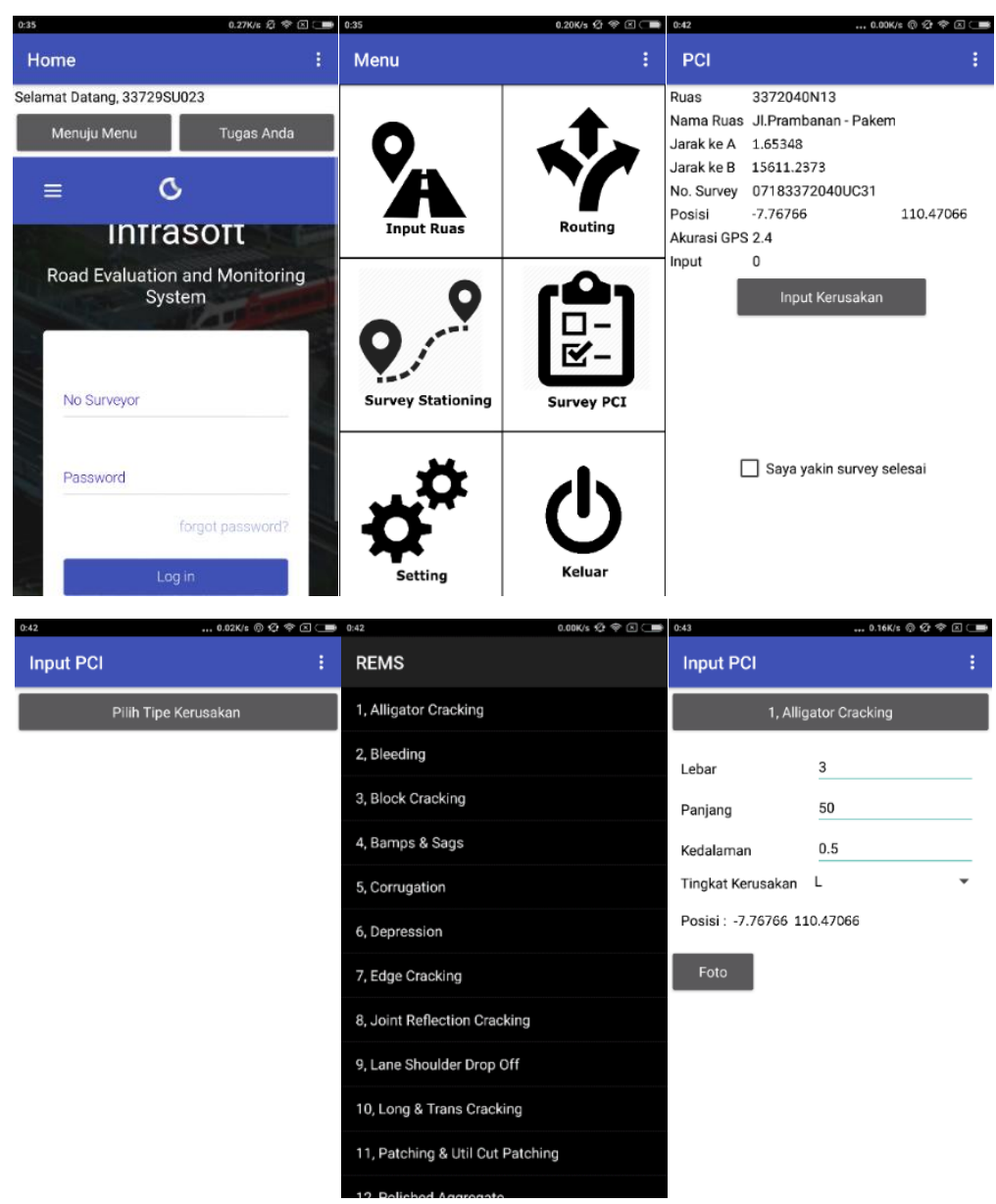

Gambar 5 Proses Input Data Kerusakan pada Aplikasi REMS 
Dari Gambar 5 dapat dilihat tampilan pada proses penginputan data kerusakan pada aplikasi REMS yaitu berupa jenis kerusakan setiap segmen serta dimensi kerusakan (panjang, lebar). Data tersebut kemudian akan diproses langsung untuk menghasilkan nilai PCI tanpa harus melakukan perhitungan secara manual.

\section{METODE PENELITIAN}

Metode penelitian yang digunakan adalah metode deskriptif analitis, yaitu suatu metode penelitian dengan cara mendeskripsikan atau memberi gambaran terhadap suatu objek penelitian yang diteliti melalui sampel atau data yang telah terkumpul dan membuat kesimpulan yang berlaku umum (Soegiyono, 2009). Jenis data yang digunakan merupakan data primer. Tahapan penelitian adalah sebagai berikut.

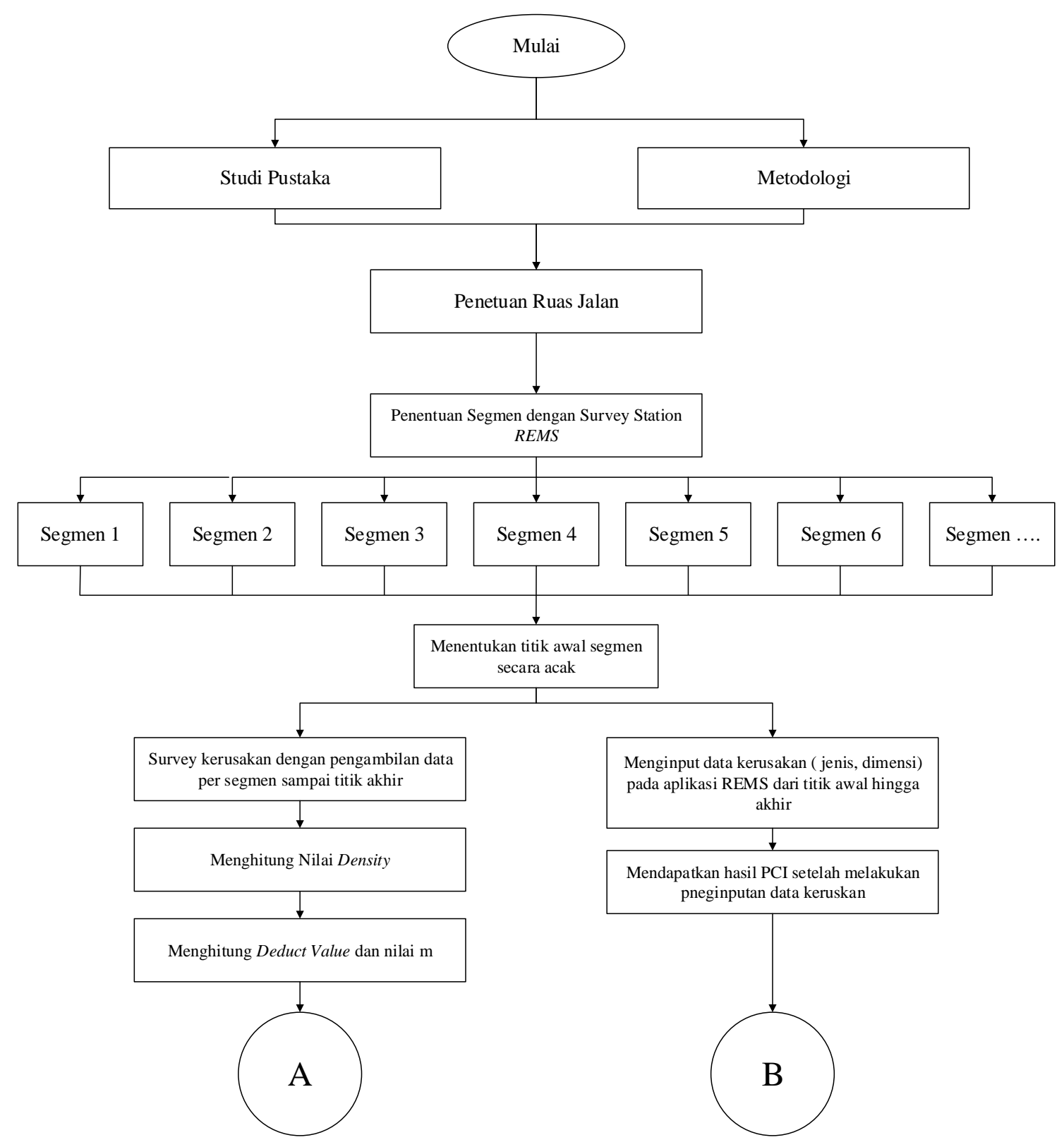




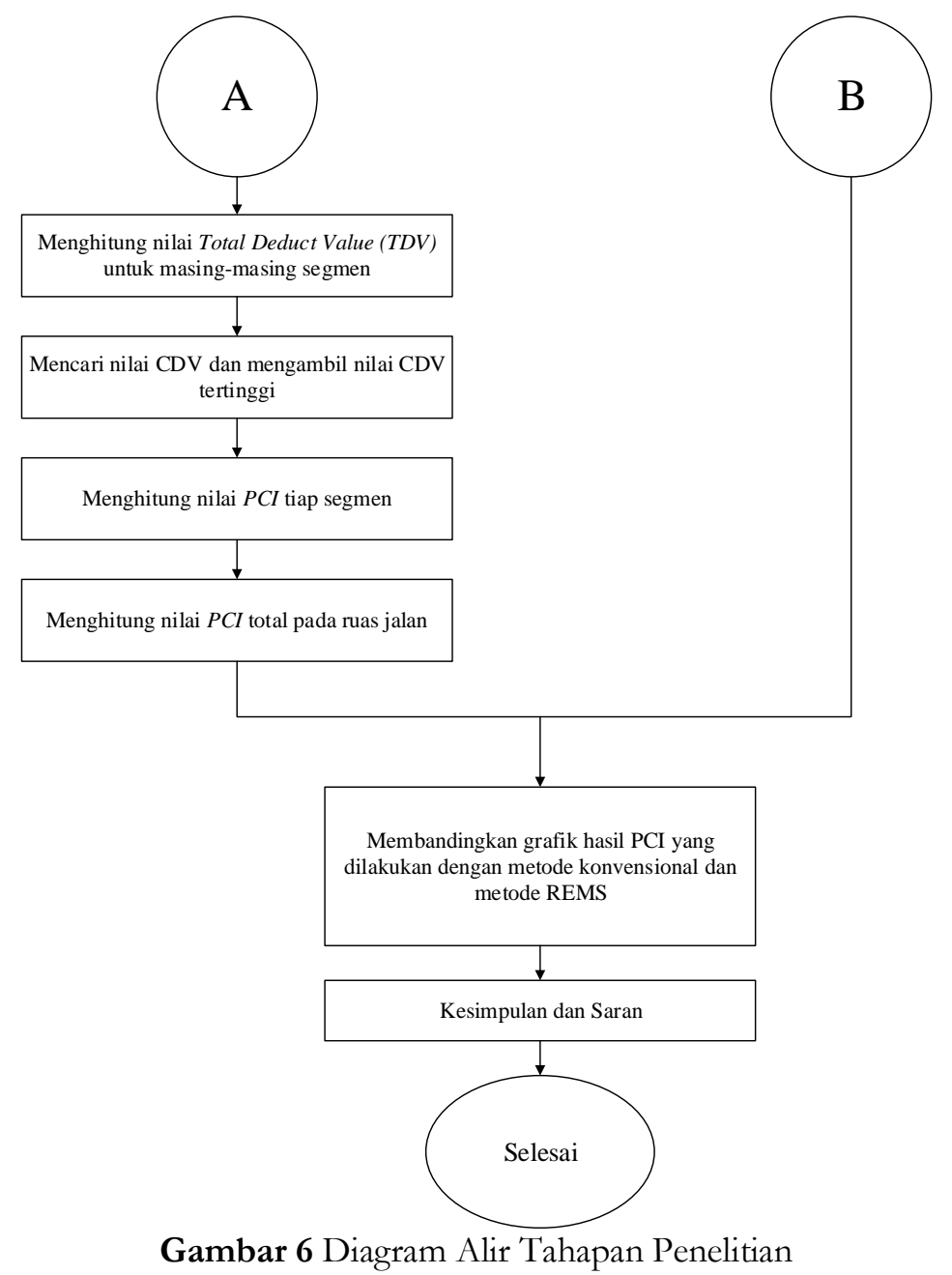

HASIL DAN PEMBAHASAN

Analisis Pavement Condition Index (PCI) Manual

Segmen yang diteliti pada ruas Jalan Prambanan - Pakem berjumlah 30 unit dengan panjang masing-masing segmen $50 \mathrm{~m}$ dan lebar jalur $4 \mathrm{~m}$. Data kerusakan tiap segmen selanjutnya dihitung hingga didapat nilai PCI per segmen, lalu dihitung nilai rata-rata keseluruhan ruas. Rekapitulasi nilai PCI tiap segmen ditunjukkan pada Tabel 1

Tabel 1 Rekapitulasi Nilai PCI Manual

\begin{tabular}{ccccc}
\hline No. & STA & CDV Maks & PCI & Keterangan \\
\hline 1 & $0+450-0+500$ & 60 & 40 & Very Poor \\
\hline 2 & $0+950-1+000$ & 38 & 62 & Fair \\
\hline 3 & $1+450-1+500$ & 78 & 22 & Serious \\
\hline 4 & $1+950-2+000$ & 45 & 55 & Poor \\
\hline 5 & $2+450-2+500$ & 48 & 52 & Poor \\
\hline 6 & $2+950-3+000$ & 16 & 84 & Satisfactory \\
\hline 7 & $3+450-3+500$ & 42 & 58 & Fair \\
\hline 8 & $3+950-4+000$ & 11 & 89 & Good \\
\hline 9 & $4+450-4+500$ & 2 & 98 & Good \\
\hline 10 & $4+950-5+000$ & 36 & 64 & Fair \\
\hline 11 & $5+450-5+500$ & 0 & 100 & Good \\
\hline 12 & $5+950-6+000$ & 0 & 100 & Good \\
\hline 14 & $6+450-6+500$ & 0 & 100 & Good \\
\hline 15 & $6+950-7+000$ & 0 & 100 & Good \\
\hline \hline
\end{tabular}




\begin{tabular}{ccccc}
\hline 16 & $7+950-8+000$ & 15 & 85 & Satisfactory \\
\hline 17 & $8+450-8+500$ & 48 & 52 & Poor \\
\hline 18 & $8+950-9+000$ & 43 & 57 & Fair \\
\hline 19 & $9+450-9+500$ & 19 & 81 & Satisfactory \\
\hline 20 & $9+950-10+000$ & 0 & 100 & Good \\
\hline 21 & $10+450-10+500$ & 0 & 100 & Good \\
\hline 22 & $10+950-11+000$ & 14 & 86 & Good \\
\hline 23 & $11+450-11+500$ & 0 & 100 & Good \\
\hline 24 & $11+950-12+000$ & 38 & 62 & Fair \\
\hline 25 & $12+450-12+500$ & 1 & 99 & Good \\
\hline 26 & $12+950-13+000$ & 0 & 100 & Good \\
\hline 27 & $13+450-13+500$ & 32 & 68 & Fair \\
\hline 28 & $13+950-14+000$ & 38 & 62 & Fair \\
\hline 29 & $14+450-14+500$ & 31 & 69 & Fair \\
\hline 30 & $14+950-15+000$ & 20 & 80 & Satisfactory \\
\hline
\end{tabular}

Dari table 1 didapatkan nilai PCI rata - rata menggunakan Persamaan 6 adalah 77.4 dengan kategori "Satisfactory"

\section{Analisis Pavement Condition Index (PCI) dengan Menggunakan Road Evaluation and Monitoring System (REMS)}

Hasil analisis data PCI dengan REMS dapat dilihat pada website infrasoft.id dengan menggunakan akun surveyor masing-masing. Hasil yang disajikan pada website infrasoft.id manunjukan untuk segmen yang tidak disurvey akan langsung memiliki nilai 100. Berikut merupakan table nilai PCI dengan menggunakan REMS

Tabel 2 Rekapitulasi Nilai PCI REMS

\begin{tabular}{|c|c|c|}
\hline Segmen & $P C I$ & Keterangan \\
\hline 10 & 52.34 & Poor \\
\hline 20 & 64.79 & Fair \\
\hline 30 & 22.14 & Serious \\
\hline 40 & 63.81 & Fair \\
\hline 50 & 70.58 & Satisfactory \\
\hline 60 & 84.18 & Satisfactory \\
\hline 70 & 63.89 & Fair \\
\hline 80 & 88.97 & Good \\
\hline 90 & 97.24 & Good \\
\hline 100 & 66.11 & Fair \\
\hline 110 & 100.00 & Good \\
\hline 120 & 100.00 & Good \\
\hline 130 & 100.00 & Good \\
\hline 140 & 100.00 & Good \\
\hline 150 & 100.00 & Good \\
\hline 160 & 84.86 & Satisfactory \\
\hline 170 & 58.16 & Fair \\
\hline 180 & 61.37 & Fair \\
\hline 190 & 80.07 & Satisfactory \\
\hline 200 & 100.00 & Good \\
\hline 210 & 100.00 & Good \\
\hline 220 & 85.68 & Good \\
\hline 230 & 100.00 & Good \\
\hline 240 & 62.70 & Fair \\
\hline 250 & 100.00 & Good \\
\hline 260 & 100.00 & Good \\
\hline 270 & 75.85 & Satisfactory \\
\hline 280 & 64.49 & Fair \\
\hline 290 & 71.74 & Satisfactory \\
\hline 300 & 85.85 & Satisfactory \\
\hline
\end{tabular}


Pada Tabel 2 didapatkan nilai PCI rata-rata menggunakan Persamaan 6 yaitu 80.03 dengan kategori "Satisfactory"

\section{ANALISIS PENANGANAN}

\section{Perbandingan Hasil Analisis PCI Manual dengan PCI REMS}

Hasil dari analisis Pavement Condition Index (PCI) secara manual kemudian dibandingkan terhadap hasil analisis Pavement Condition Index (PCI) dengan menggunakan REMS. Kedua hasil ini dibandingkan untuk mengetahui apakah adanya keakuratan perhitungan nilai PCI yang dianalisis dengan REMS

Tabel 3 Perbandingan nilai PCI manual dan PCI dengan REMS Setiap Segmen

\begin{tabular}{|c|c|c|c|c|c|c|}
\hline Segmen & STA & $\begin{array}{c}P C I \\
\text { Manual }\end{array}$ & Keterangan & $\begin{array}{c}P C I \\
R E M S\end{array}$ & Keterangan & Simpangan \\
\hline 10 & $0+450-0+500$ & 40 & Very Poor & 52.34 & Poor & $23.57 \%$ \\
\hline 20 & $0+950-1+000$ & 62 & Fair & 64.79 & Fair & $4.31 \%$ \\
\hline 30 & $1+450-1+500$ & 22 & Serious & 22.14 & Serious & $0.62 \%$ \\
\hline 40 & $1+950-2+000$ & 55 & Poor & 63.81 & Fair & $13.81 \%$ \\
\hline 50 & $2+450-2+500$ & 52 & Poor & 70.58 & Satisfactory & $26.33 \%$ \\
\hline 60 & $2+950-3+000$ & 84 & Satisfactory & 84.18 & Satisfactory & $3.78 \%$ \\
\hline 70 & $3+450-3+500$ & 58 & Fair & 63.89 & Fair & $9.22 \%$ \\
\hline 80 & $3+950-4+000$ & 89 & Good & 88.97 & Good & $0.04 \%$ \\
\hline 90 & $4+450-4+500$ & 98 & Good & 97.24 & Good & $0.77 \%$ \\
\hline 100 & $4+950-5+000$ & 64 & Fair & 66.11 & Fair & $3.19 \%$ \\
\hline 110 & $5+450-5+500$ & 100 & Good & 100.00 & Good & $0.00 \%$ \\
\hline 120 & $5+950-6+000$ & 100 & Good & 100.00 & Good & $0.00 \%$ \\
\hline 130 & $6+450-6+500$ & 100 & Good & 100.00 & Good & $0.00 \%$ \\
\hline 140 & $6+950-7+000$ & 100 & Good & 100.00 & Good & $0.00 \%$ \\
\hline 150 & $7+450-7+500$ & 100 & Good & 100.00 & Good & $0.00 \%$ \\
\hline 160 & $7+950-8+000$ & 85 & Satisfactory & 84.86 & Satisfactory & $0.17 \%$ \\
\hline 170 & $8+450-8+500$ & 52 & Poor & 58.16 & Fair & $10.60 \%$ \\
\hline 180 & $8+950-9+000$ & 57 & Fair & 61.37 & Fair & $7.12 \%$ \\
\hline 190 & $9+450-9+500$ & 81 & Satisfactory & 80.07 & Satisfactory & $1.14 \%$ \\
\hline 200 & $9+950-10+000$ & 100 & Good & 100.00 & Good & $0.00 \%$ \\
\hline 210 & $10+450-10+500$ & 100 & Good & 100.00 & Good & $0.00 \%$ \\
\hline 220 & $10+950-11+000$ & 86 & Good & 85.68 & Good & $0.37 \%$ \\
\hline 230 & $11+450-11+500$ & 100 & Good & 100.00 & Good & $0.00 \%$ \\
\hline 240 & $11+950-12+000$ & 62 & Fair & 62.70 & Fair & $1.12 \%$ \\
\hline 250 & $12+450-12+500$ & 99 & Good & 100.00 & Good & $1.00 \%$ \\
\hline 260 & $12+950-13+000$ & 100 & Good & 100.00 & Good & $0.00 \%$ \\
\hline 270 & $13+450-13+500$ & 68 & Fair & 75.85 & Satisfactory & $10.34 \%$ \\
\hline 280 & $13+950-14+000$ & 62 & Fair & 64.49 & Fair & $3.86 \%$ \\
\hline 290 & $14+450-14+500$ & 69 & Fair & 71.74 & Satisfactory & $3.82 \%$ \\
\hline 300 & $14+950-15+000$ & 80 & Satisfactory & 81.85 & Satisfactory & $2.26 \%$ \\
\hline
\end{tabular}

Pada Tabel 3 menunjukan perbandingan antara PCI manual dan REMS ada 15 segmen dari total 30 segmen yang mempunyai nilai simpang $>1 \%$. 


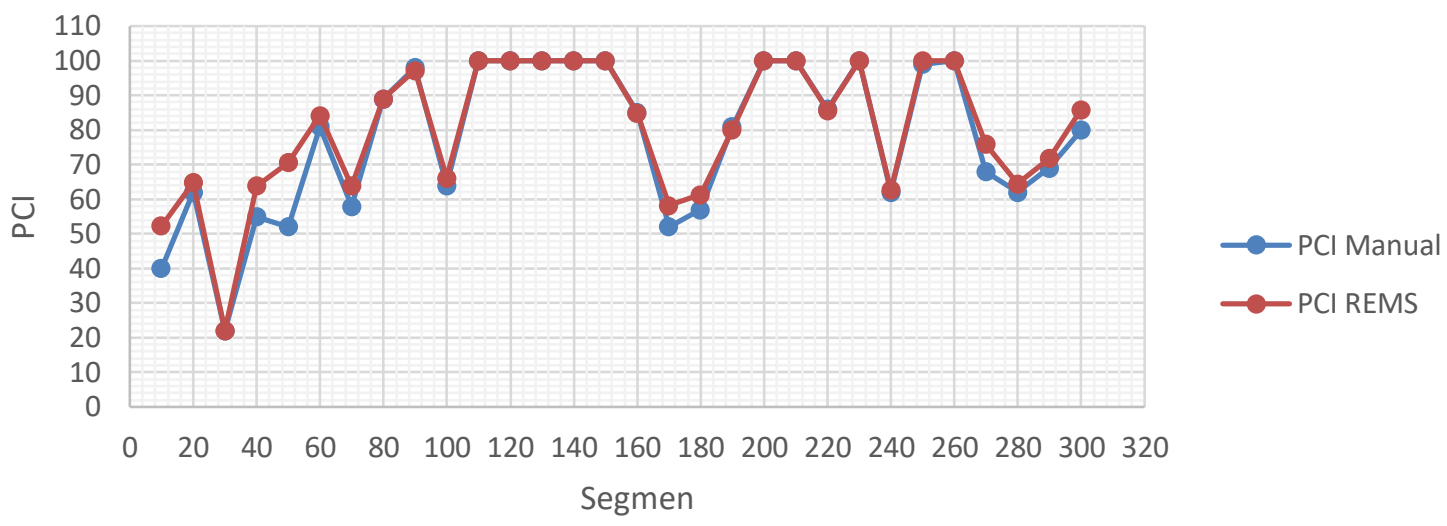

Gambar 7 Grafik Perbandingan Nilai PCI Manual dan PCI REMS

Dari Tabel 3 dan Gambar 7 menunjukan bahwa perhitungan yang dilakukan oleh aplikasi REMS memiliki perbedaan dalam pembacaan grafik (DV dan CDV) dimana pembacaan grafik oleh komputer lebih akurat dari mata manusia. Adanya perbedaan simpangan hingga $>1 \%$ dalam nilai PCI REMS dengan PCI manual juga disebabkan oleh pemilihan nilai CDV. Dalam metode PCI untuk pemilihan nilai CDV, dipilih dari nilai paling tinggi tetapi untuk PCI REMS diambil nilai dengan urutan pertama. Berikut merupakan hasil pembuktiannya:

Diketahui nilai $P C I$ untuk tiap unit dapat diketahui dengan persamaan di bawah ini:

$P C I_{(s)}=100-C D V M a k s$

dengan :

$\mathrm{PCI}_{(s)} \quad=$ Pavement Condition Index untuk tiap segmen.

$C D V$ Maks $\quad=$ Corrected Deduct V alue maksimal untuk tiap segmen.

Tabel 4 Hasil Perhitungan DV segmen STA 0+450 - 0+500

\begin{tabular}{ccccccc}
\hline STA & No & \multicolumn{2}{c}{ DV } & TDV & Q & $\boldsymbol{C D V}$ \\
\hline \multirow{2}{*}{$0+450-0+500$} & 1 & 58 & 8 & 66 & 2 & 48 \\
& 2 & 58 & 2 & 60 & 1 & 60 \\
\hline
\end{tabular}

Pada Tabel 4 menunjukkan nilai CDV yang paling tinggi adalah 60 .

Nilai CDV paling tinggi adalah 60 maka:

PCI $=100-$ CDV Maks

PCI $=100-60$

$\mathrm{PCI}=40$

Untuk analisis PCI oleh REMS digunakan CDV dengan urutan pertama yaitu 48 :

PCI $=100-$ CDV urutan pertama

$\mathrm{PCI}=100-48$

$\mathrm{PCI}=52$

Mendekati 52.34

\begin{tabular}{cccccccc}
\hline STA & No & TDV & Q & CDV & PCI Manual & $\begin{array}{c}\text { PCI CDV } \\
\text { Tertinggi }\end{array}$ & PCI REMS \\
\hline \multirow{2}{*}{$0+450-0+500$} & 1 & 66 & 2 & 48 & 60 & 52 & 52.34 \\
\hline \multirow{2}{*}{$1+950-2+000$} & 2 & 60 & 1 & 60 & 55 & 60 & 63.81 \\
\hline \multirow{2}{*}{$2+450-2+500$} & 2 & 45 & 1 & 45 & 52 & 66 & 70.58 \\
& 2 & 53 & 3 & 34 & & \multirow{2}{*}{6} \\
\hline
\end{tabular}




\begin{tabular}{|c|c|c|c|c|c|c|c|}
\hline & 3 & 48 & 1 & 48 & & & \\
\hline \multirow{3}{*}{$2+950-3+000$} & 1 & 33 & 3 & 17 & \multirow{3}{*}{81} & \multirow{3}{*}{83} & \multirow{3}{*}{84.18} \\
\hline & 2 & 26 & 2 & 19 & & & \\
\hline & 3 & 17 & 1 & 17 & & & \\
\hline \multirow{3}{*}{$3+450-3+500$} & 1 & 58 & 3 & 36 & \multirow{3}{*}{58} & \multirow{3}{*}{64} & \multirow{3}{*}{63.89} \\
\hline & 2 & 55 & 2 & 39 & & & \\
\hline & 3 & 42 & 1 & 42 & & & \\
\hline \multirow{2}{*}{$8+450-8+500$} & 1 & 57 & 2 & 42 & \multirow[b]{2}{*}{52} & \multirow{2}{*}{58} & \multirow{2}{*}{58.16} \\
\hline & 2 & 48 & 1 & 48 & & & \\
\hline \multirow{3}{*}{$8+950-9+000$} & 1 & 66 & 3 & 40 & \multirow{3}{*}{57} & \multirow{3}{*}{60} & \multirow{3}{*}{61.37} \\
\hline & 2 & 60 & 2 & 43 & & & \\
\hline & 3 & 32 & 1 & 32 & & & \\
\hline \multirow{2}{*}{$13+450-13+500$} & 1 & 36 & 2 & 26 & \multirow{2}{*}{68} & \multirow{2}{*}{74} & \multirow{2}{*}{75.85} \\
\hline & 2 & 32 & 1 & 32 & & & \\
\hline \multirow{2}{*}{$14+450-14+500$} & 1 & 39 & 2 & 31 & \multirow{2}{*}{69} & \multirow{2}{*}{69} & \multirow{2}{*}{71.74} \\
\hline & 2 & 29 & 1 & 29 & & & \\
\hline
\end{tabular}

Tabel 5 Tabel Hasil Pembuktian Perbedaan Nilai PCI

Pada Tabel 5 menunjukkan hasil pembuktian perbedaan nilai PCI Manual dan PCI REMS berdasarkan pemilihan nilai CDV.

\section{SIMPULAN}

Hasil analisis kondisi permukaan jalan Prambanan - Pakem menggunakan Metode Pavement Condition Index (PCI) diperoleh nilai sebesar 77.4 atau dalam kategori "Satisfactory" atau "Memuaskan". Sedangkan hasil analisis PCI menggunakan aplikasi REMS diperoleh nilai sebesar 80.03 dalam kategori "Satisfactory" atau "Memuaskan". Perbandingan nilai antara PCI manual dan PCI REMS didapat sebanyak terdapat 15 segmen dari 30 segmen memiliki perbedaan simpang yang melebihi $1 \%$. Segmen yang memiliki simpangan $>1 \%$ disebabkan oleh pengambilan nilai CDV serta ketelitian dalam membaca grafik (DV dan CDV). Dalam metode PCI untuk pemilihan nilai CDV, dipilih dari nilai paling tinggi tetapi untuk PCI REMS diambil nilai dengan urutan pertama.

\section{REKOMENDASI}

1. Aplikasi REMS untuk penggunaan secara umum sudah cukup membantu karna proses output yang sangat cepat.

2. Perlunya pengembangan lebih lanjut untuk aplikasi REMS agar lebih akurat hasilnya dalam analisis PCI

3. Untuk penelitian selanjutnya dapat dilakukan kedua ruas jalan, ruas jalan Pakem - Prambanan dan Prambanan - Pakem agar diperoleh hasil yang lebih representatif.

\section{UCAPAN TERIMA KASIH}

Ucapan terima kasih kepada Ir. Ary Setyawan, M.Sc, PhD. dan Ir. Suryoto, MT yang telah membimbing dan memberi arahan serta masukan dalam penelitian ini.

\section{REFERENSI}

ASTM D 6433 - 07, 2007. Standard Practice for Roads and Parking Lots Pavement Condition Index Surveys. United States: Association of Standard Testing Materials.

Bina Marga. 2011. Pedoman Desain Perkerasan Jalan Lentur, Kementerian Pekerjaan Umum, Jakarta.

Bina Marga. 2013. Manual Desain Perkerasan Jalan, Kementerian Pekerjaan Umum, Jakarta

Bolla, M. E. 2012. Perbandingan Metode Bina Marga Dan Metode Pci (Pavement Condition Index) Dalam Penilaian Kondisi Perkerasan Jalan (Studi Kasus Ruas Jalan Kaliurang, Kota Malang). Jurnal Teknik Sipil, 1(3), 104-116.

Irzami. 2010. Penilaian Kondisi Perkerasan Dengan Menggunakan Metode Indeks Kondisi Perkerasan Pada Ruas Jalan Simpang Kulim - Simpang Batang. (Magister Tesis, Universitas Islam Riau).

Nainggolan, J. 2015. Evaluasi Kondisi Perkerasan Lentur Dan Prediksi Umur Layan Jalintim Provinsi Sumatera Selatan (Studi Kasus: Ruas Jalan Batas Provinsi Jambi-Peninggalan) (Doctoral dissertation, Universitas Sebelas Maret). 
Putri, Elsa Eka. 2016. Analisis Tebal Lapis Tambah Dan Umur Sisa Perkerasan Akibat Beban Berlebib Kendaraan (Studi Kasus Ruas Jalan Nasional Di Provinsi Sumatera Barat). Proceedings ACES (Annual Civil Engineering Seminar). Vol. 1.

Republik Indonesia. 2004. Undang-Undang No. 38 Tabun 2004 tentang jalan. Lembaran Negara RI Tahun 2004, No 83. Sekretariat Negara. Jakarta.

Setyowati, S. 2011. Penilaian Kondisi Perkerasan Dengan Menggunakan Metode Pavement Condition Index (PCI), Penigkatan Jalan Dan Perbitungan Rancangan Anggaran Biaya Pada Ruas Jalan Solo - Karanganyar Km 4+400 - 11+050

Setyawan,A.dkk, S. 2017. The Design of Road Evaluation and Monitoring System based on Geographical Information System

Shahin, M. Y. 1994. Pavement management for airports, roads, and parking lots (Vol. 501). New York: Springer.

Suswandi. A. 2008. Evaluasi Tingkat Kerusakan Jalan Dengan Methode Pavement Condition Index (PCI) Untuk Menunjang Pengambilan Keputusan (Studi Kasus: Jalan Lingkar Selatan, Yogyakarta). Forum Teknik Sipil No. XVIII/3-Sept 2008. 